\title{
Analysis of Delivery in Singleton Pregnancies Achieved by In Vitro Fertilization
}

\author{
Sergei Slavov*iD, Gergana Ingilizova² ${ }^{1}$, Galina Yaneva ${ }^{3} \mathbb{D}$ \\ ${ }^{1}$ Department of Obstetrics and Gynecology, Medical University, Maichin Dom Hospital, Sofia, Bulgaria; ${ }^{2}$ Department of \\ Obstetrics and Gynecology, Multiprofile hospital for active treatment "Vita", Sofia, Bulgaria, Vita Hospital, Sofia, Bulgaria; \\ ${ }^{3}$ Department of Biology, Faculty of Pharmacy, Medical University, Varna, Bulgaria
}

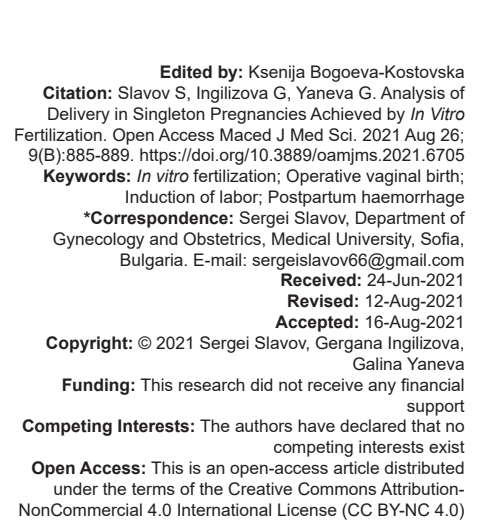

\section{Introduction}

The number of women giving birth after in vitro fertilization (IVF) is steadily increasing worldwide. The decision on the timing and mode of delivery in these patients should be made after taking into account various risk factors preceding pregnancy, as well as the presence of pregnancy complications. The findings of a single review imply that women who undergo assistive reproductive techniques to achieve pregnancy have higher levels of anxiety in pregnancy [1]. The incidence of elective cesarean section at the patient's request is increased in most countries in pregnancies after IVF. This is particularly common in older patients, where the fear of poor fetal outcome lowers the threshold for deciding on interventions such as induction of labor and operative delivery. Most studies showed that the incidence of cesarean sections in singleton pregnancies after IVF is increased compared to pregnancies after spontaneous conception [2], [3], [4], [5], [6], [7], [8], [9], [10]. More common in these pregnancies are complications such as severe postpartum hemorrhage (PPH) and blood transfusion [5], [11], [12].
The aim of this study was to compare IVF and spontaneous singleton pregnancies according to specific features related to delivery.

\section{Material and Methods}

\section{Study design}

We conducted retrospective study at "Maichin Dom" University Hospital in Sofia, Bulgaria for the period from January 2013 to December 2017.

\section{Cases}

We have analyzed 402 singleton IVF pregnancies - the study group (SG) and compared them with 523 random spontaneous singleton pregnancies without a history of infertility treatment - the control group (CG). 


\section{Inclusion criteria}

The presence of only singleton pregnancies at the time of delivery, available data for the method of conception (spontaneous pregnancy or an IVF procedure), the pregnancy has ended with delivery after 22 gestational weeks and/or birth weight of $>600 \mathrm{~g}$.

\section{Exclusion criteria}

Multiple pregnancies.

\section{Data collection}

Age and parity were examined in all patients. In the SG 180 patients were at age $\leq 35$ years and 222 were >35-years-old, whereas in the CG 415 were at age $\leq 35$ years and 108 were $>35$-years-old. There was a prevalence of primiparous women in SG - 365 (91\%) compared with CG - 303 (58\%). Operative vaginal delivery (OVD) was performed by vacuum extractor with Silastic cup or Simpson's forceps. Placenta previa was diagnosed when the lower edge of the placenta was found by ultrasound to be $<2 \mathrm{~cm}$ from the internal cervical OS. Based on the criteria of the American College of Obstetricians and Gynecologists we defined $\geq 1,000 \mathrm{ml}$ of blood loss after birth as severe postpartum hemorrhage [13]. Condition of the newborn was determined by APGAR score at $1 / 5 \mathrm{~min}$ of birth. The stay of the newborn in the neonatal intensive care unit (NICU) was monitored. The gestational age during the pregnancy follow-up was determined based on the date of the last menstrual period and/or the date of the embryo transfer. The weight of the newborn was determined immediately after birth by measuring with an accuracy of $10 \mathrm{~g}$. The Institutional review board of University hospital "Maichin Dom," Sofia, Bulgaria approved the collection of data.

\section{Statistical analysis}

Statistical analysis was performed using the SPSS for Windows, v 13. Statistical methods used include descriptive statistical analysis. Mann-Whitney test was used for continuous variables. The counting data were represented by $n(\%)$ and $\chi^{2}$ tests were used for categorical variables. One-Sample Kolmogorov Smirnov test was used to test if variables are normally distributed. Statistical significance was established at $p<0.05$

\section{Results}

\section{Cesarean section rate}

There was a significantly higher rate of cesarean section in the SG compared with the CG (Odds ratio
[OR], 1.73; 95\% Confidence interval [Cl], 1.4-2.14; $p<0.001$ ) (Table 1). Elective cesarean sections were performed in $66.1 \%$ in SG compared with $63,8 \%$ in the CG. Statistical difference between the groups was maintained even after taking into account factors such as age and parity (Table 1). Even in women who had prior vaginal birth the incidence of cesarean section in the SG group was higher - 73\% $(n=27)$ compared to $45.5 \%(n=100)$ of cases in the CG $(p=0.002)$. The mean duration of pregnancy in the SG was 258 days and in the CG - 267 days ( $p<0.001)$. The mean birth weight was $2886 \mathrm{~g}$ in the SG compared with $3083 \mathrm{~g}$ in the CG $(p<0.001)$.

Table 1: Comparison between IVF singletons and spontaneous pregnancies - all indicators

\begin{tabular}{llll}
\hline Variable & IVF pregnancies n (\%) & $\begin{array}{l}\text { Spontaneous } \\
\text { pregnancies n }(\%)\end{array}$ & p value \\
\hline Cesarean section & $329 / 402(81.8 \%)$ & $247 / 523(47.2 \%)$ & $<0.001$ \\
Cesarean section $\leq 35$ years & $131 / 180(72.8 \%)$ & $186 / 417(44,6 \%)$ & $<0.001$ \\
Cesarean section $>35$ years & $198 / 222(89.2 \%)$ & $62 / 108(57.4 \%)$ & $<0.001$ \\
Cesarean section primipara & $302 / 365(82.7 \%)$ & $148 / 303(48.8 \%)$ & $<0.001$ \\
Operative vaginal delivery & $15 / 73(20.5 \%)$ & $25 / 276(9.1 \%)$ & 0.018 \\
Labor induction & $2 / 73(2.7 \%)$ & $18 / 276(6.5 \%)$ & $>0.05$ \\
Manual removal of the placenta & $3 / 73(4.1 \%)$ & $3 / 276(1.1 \%)$ & $>0.05$ \\
Severe PPH in Cesarean section & $20 / 329(6 \%)$ & $5 / 247(2 \%)$ & 0.018 \\
Blood transfusion after Cesarean & $20 / 329(6 \%)$ & $5 / 247(2 \%)$ & 0.018 \\
section & & & \\
Placenta previa & $25 / 402(6.2 \%)$ & $9 / 523(1.7 \%)$ & $<0.001$ \\
\hline IVF: In vitro fertilization. & & &
\end{tabular}

\section{OVD}

Our study established incidence of OVD in the SG $20.5 \%(n=15)$, and in the CG 9.1\% $(n=25)$, (OR, 2.27, 95\% Cl, 1.14-4.52; $p=0.018$ ). In the SG, all pregnancies were with no obstetric complications except for one case with gestational diabetes. In the CG, one of the births was premature and other two cases had gestational diabetes. In the SG, leading indication for OVD was a decrease in fetal heart rate (FHR) diagnosed with cardiotocography (CTG) - 8 cases (53.3\%), while in the CG this indication occurred in only 4 cases $(16 \%)$. None of the neonates in the SG had APGAR score $<7$ at birth or was admitted to NICU. Two of the neonates in the CG were with APGAR score at the $1^{\text {st }}$ and $5^{\text {th }}$ min. -6 and 7 . The indications for OVD in these cases were decrease in FHR on CTG. The newborns were admitted to NICU for 13 and 3 days, respectively.

\section{Induction of labor}

A lower but not significant frequency of induction of labor was found in IVF pregnancies. In the SG, induction of labor was done in $2.7 \%(n=2)$ of cases, compared with $6.5 \%(18)$ in the CG ( $p>0.05)$.

\section{Third period of labor}

Although there were no significant differences between the two groups according to the rate of manual removal of the placenta, there were more cases of this 
pathology in the IVF group (4.1\%) compared with the CG $(1.1 \%),(p>0.05 ;$ Table 1$)$.

\section{Blood loss at labor}

In vaginal deliveries, no difference in average blood loss (Table 2) and in the rate of severe $\mathrm{PPH}$ was found between the study and CG.

Table 2: Average blood loss at delivery in IVF and spontaneous pregnancies

\begin{tabular}{lllllllll}
\hline Blood loss & Group & $\mathrm{N}$ & Mean & Median & SD & Min & Max & p value \\
\hline $\begin{array}{l}\text { Cesarean } \\
\text { section }\end{array}$ & $\begin{array}{l}\text { Spontaneous } \\
\text { pregnancies } \\
\text { IVF }\end{array}$ & 247 & 492.54 & 400.00 & 278.14 & 400.00 & 4000.00 & 0.008 \\
& 329 & 542.08 & 500.00 & 324.80 & 200.00 & 3500.00 & \\
$\begin{array}{l}\text { Vaginal } \\
\text { delivery }\end{array}$ & $\begin{array}{l}\text { Spontancies } \\
\text { pregnancies } \\
\text { IVF }\end{array}$ & 276 & 261.50 & 250.00 & 77.66 & 0.00 & 1000.00 & 0.077 \\
& 73 & 287.67 & 250.00 & 132.23 & 200.00 & 1000.00 & \\
\hline
\end{tabular}

When analyzing the cases of cesarean births, a higher mean blood loss was found in the SG (542 ml) compared to the CG (492 $\mathrm{ml})(p=0.008$; Table 2).

Severe PPH was found in 20 cases $(6.07 \%)$ in the SG, compared to $5(2 \%)$ cases in the CG when cesarean section was performed ([OR, 3.0; 95\% Cl, $1.11-8.11 ; p=0.018)$. Detailed analysis found 13 cases with severe $\mathrm{PPH}$ in the SG where various forms of placenta previa were diagnosed, as well as one case of placental abruption. There were four cases with severe $\mathrm{PPH}$ and diagnosed placenta previa in the CG. Our study found $25(6.2 \%)$ cases with placenta previa in the SG compared to $9(1.7 \%)$ in the CG (OR, 3.61; 95\% $\mathrm{Cl}, 1.67-7.83 ; \mathrm{p}<0.001)$. The rate of blood transfusion was higher in the SG $-6.07 \%(n=20)$ than in the CG $2.0 \%(n=5)(O R, 3.0 ; 95 \% \mathrm{Cl}, 1.11-8.11 ; p=0.018)$.

\section{Discussion}

The increased rate of cesarean sections in IVF singleton pregnancies is proven by numerous studies. Whether the higher incidence of cesarean sections among women with infertility is justified has not yet been fully examined. One large study demonstrates that elective cesarean section does not reduce the increased perinatal risk in singleton pregnancies achieved by infertility treatment. These data may serve as a motive for reducing the frequency of cesarean sections in these pregnancies [10]. When pregnancies after IVF are delivered not by the team that performed the procedure, but by doctors on duty, the frequency of cesarean section is much lower and the mode of delivery is mainly medically justified. This leads to the assumption that in women with infertility, medical reasons are not the only ones, which influence the type of birth, but also socio-emotional factors [14].

Regarding vaginal birth, singleton pregnancies after IVF have some peculiarities. The frequency of
OVD, according to some authors, is higher in pregnant women after IVF [15], which our findings confirm as well. Earlier studies showed the opposite results, finding a lower incidence of OVD among IVF pregnant women [16]. Our study found a better condition of the newborn in pregnant women after IVF and OVD than that of newborns from spontaneous pregnancies. It can be assumed that OVD in IVF pregnant women is performed at an earlier stage of the delivery due to fear of complications for the fetus, which leads to a better condition of the newborn evaluated with APGAR score at $1^{\text {st }}$ and $5^{\text {th }}$ min after the birth. Most likely, even slight deviations from the monitor recording during labor lead to a transition to OVD.

Many studies of singleton pregnancies after IVF have reported a higher incidence of induction of labor for a variety of reasons [5], [6], [8]. Except for medical reasons, in IVF pregnancies induction of labor often is performed without strong indications. Unlike the results of most authors, our study found the opposite results. In our country, induction of labor is much less common in pregnancies after IVF compared to spontaneous singleton pregnancies. The reason probably lies in the higher frequency of cesarean section in this group. When labor does not begin spontaneously, elective cesarean section is much more common, and induction of labor is not the method of choice in these patients.

Our study did not find higher rate of manual removal of the placenta during vaginal birth, unlike other studies [15], [17].

Our results have showed that severe blood loss during cesarean section is mainly due to increased rate of placenta previa. These cases are much more common in IVF singleton pregnancies than spontaneous pregnancies and therefore the incidence of excessive blood loss in this group is higher [7]. The connection between severe maternal morbidity during labor and previous treatment for infertility or IVF is interesting. Belanoff et al. 2016 [11], investigated whether there is a difference in severe maternal morbidity at birth in women who became pregnant in different ways - after IVF, spontaneous pregnancies with reduced fertility and spontaneous pregnancies infertile women. The most commonly used indicator of severe maternal morbidity was the need for a blood transfusion. The study found that IVF is associated with the highest incidence of severe maternal morbidity regardless of the method of delivery - vaginal birth or cesarean section. Some of the reasons for these differences in the course of delivery are known, while others will be clarified in the future. Some of the known factors include higher incidence of placenta previa [18], [19] and higher incidence of cesarean section [3], [4], [6], [8], [9], [10] in IVF pregnancies and advanced maternal age [20], [21]. Moreover, patients who use IVF as a method of pregnancy are likely to have concomitant diseases and fertility disorders that require the use of IVF. The results of the other two groups in the study did 
not differ significantly, which again drew the attention of clinicians to the role of IVF in increasing the risk of complications at birth. Our research shows three times higher incidence of blood transfusion after cesarean section in IVF pregnancies compared with spontaneous pregnancies, which coincides completely with the results of this study.

Martin et al. 2016 [12], also prove that the severe maternal illness in IVF singleton births is much higher than that of singleton births from pregnancies without IVF. It is interesting that for the period of the study from 2008 to 2012 among IVF singleton births the outcomes are improving. This may be due to better IVF techniques over time, the smaller number of embryos being transferred, and the predominance of lighter ovarian stimulations. This leads to a reduction in cases of hyperstimulation syndrome, pregnancies occur at more physiological estrogen levels, leading to better implantation and early placental development. Our study found three times higher rate of severe $\mathrm{PPH}$ and blood transfusion in cesarean section in women with singleton pregnancies after IVF compared to spontaneous singleton pregnancies. We did not find such differences in vaginal births, in contrast to the results of some authors [22], who prove that IVF is a risk factor for abnormal postpartum hemorrhage in vaginal births.

\section{Conclusion}

Singleton pregnancies after IVF pose a significantly higher risk of cesarean delivery. OVD is more common among IVF singleton pregnancies when compared with spontaneous singleton pregnancies. There is no difference in the rate of induction of labor and manual removal of the placenta when comparing IVF singleton pregnancies and spontaneous ones. The higher incidence of severe PPH and blood transfusion at birth is mainly due to the higher incidence of various forms of placenta previa among these pregnancies.

\section{References}

1. Younger M, Hollins-Martin C, Choucri L. Individualised care for women with assisted conception pregnancies and midwifery practice implications: An analysis of the existing research and current practice. Midwifery. 2015;31(2):265-70. https://doi. org/10.1016/j.midw.2014.06.008

2. Kostov I, Ivanov ST. Prevention and prophylaxis in obstetrics and gynecology. Akusherst Ginekol. 2018;57(2):57-8.

3. Helmerhorst FM, Perquin DA, Donker D, Keirse M. Perinatal outcome of singletons and twins after assisted conception: A systematic review of controlled studies.

BMJ. 2004;328(7434):261.

https://doi.org/10.1136/ bmj.37957.560278.ee

PMid: 14742347

4. Jackson RA, Gibson KA, Wu YW, Croughan M. Perinatal outcomes in singletons following in vitro fertilization: A metaanalysis. Obstet Gynecol. 2004;103(3):551-63. https://doi. org/10.1097/01.aog.0000114989.84822.51

PMid:14990421

5. Yunakova M, Gogova G, Antonova I, Veleva G, Kostov I, Shterev A. Age as a predictive marker of assisted reproductive technologies outcome. Akusherstvo Ginekol. 2017;56(6):17-21.

6. Kostov I, Yunakova M, Georgiev B, Petrova Z. Analysis of the quality of medical services in obstetrics and gynecology practice in Bulgaria-a study in organizational, clinical and deontological aspects. Akusherstvo Ginekol. 2017;56(6):9-16.

7. Shevell T, Malone F, Vidaver J, Porter T, Luthy D, Comstock C, et al. Assisted reproductive technology and pregnancy outcome. Obstetr Gynecol. 2005;106(5):1039-45. https://doi. org/10.1097/01.aog.0000183593.24583.7c PMid: 16260523

8. Silberstein T, Sheiner E, Levy A, Herlev A, Saphier O. Perinatal outcome of pregnancies following in vitro fertilization and ovulation induction. J Matern Fetal Neonatal Med. 2014;27(13):1316-9. https://doi.org/10.3109/14767058.2013.85 6415

PMid:24175873

9. Sullivan E, Chapman M, Wang YA, Adamson G. Populationbased study of cesarean section after in vitro fertilization in Australia. BIRTH. 2010;37(3):184-91. https://doi. org/10.1111/j.1523-536x.2010.00405.x PMid:20887534

10. Vilchez G, Dai J, Hoyos LR, Babbar S, Bahado-Singh R, Maulik $\mathrm{D}$, et al. Optimal delivery mode in singleton pregnancies conceived after infertility treatment: Is the "precious baby" effect justified? Am J Obstetr Gynecol. 2016;214(1):445-6. https://doi. org/10.1016/j.ajog.2015.10.906

11. Belanoff C, Declercq E, Diop H, Gopal D, Kotelchuck M, Luke B. Severe maternal morbidity and the use of assisted reproductive technologyinMassachusetts. ObstetGynecol.2016;127(3):527-34. https://doi.org/10.1097/aog.0000000000001292 PMid:26855105

12. Martin A, Mansour M, Kissin D, Jamieson DJ, Callaghan WM, Boulet SL. Trends in severe maternal morbidity after assisted reproductive technology in the United States, 2008-2012. Obstet Gynecol. 2016;127(1):59-66. https://doi.org/10.1097/ aog.0000000000001197 PMid:26646124

13. Bulletins-Obstetrics CP. Practice bulletin No. 183: "Postpartum hemorrhage". Obstet Gynecol. 2017;130:e168-86. https://doi. org/10.1097/aog.0000000000002351 PMid:28937571

14. Dimitrov A. Contemporary Problems of Abdominal Delivery, D.Sc. Thesis. Bulgaria: Medical University, Sofia; 2003. p. 154-5. https://doi.org/10.1093/hropen/hoy012

15. Vannuccini S, Ferrata C, Parelli F, Pinzauti S, Severi F, Reis F, et al. Peripartum and postpartum outcomes in uncomplicated term pregnancy following ART: A retrospective cohort study from two Italian obstetric units. Hum Reprod. 2018;3:1-8. PMid:30895253

16. Koudstaal J, Braat DD, Bruinse HW, Naaktgeboren N, Vermeiden JP, Visser GH. Obstetric outcome of singleton pregnancies after IVF: A matched control study in four Dutch university hospitals. Hum Reprod. 2000;15(8):1819-25. https:// doi.org/10.1093/humrep/15.8.1819

PMid:10920110 
17. Shufaro $Y$, Oron S, Sapir O, Pinkas H, Ben-Haroush A, Shochat T, et al. IVF is an Independent Risk Factor for Third Stage of Labor Complications Following Successful Vaginal Deliveries. Geneva: ESHRE; 2017. https://doi.org/10.26226/ morressier.5912d9efd462b8029238684b

18. Korosec S, Frangez HB, Verdenik I, Kladnik U, Kotar V, Virant-Klun I, et al. Singleton pregnancy outcomes after in vitro fertilization with fresh or frozen-thawed embryo transfer and incidence of placenta praevia. BioMed Res Int. 2014;2014:431797 https://doi.org/10.1155/2014/431797 PMid:24822209

19. Sazonova A, Kallen K, Thurin-Kjellberg A, Wennerholm UB, Bergh C. Obstetric outcome in singletons after in vitro fertilization with cryopreserved/thawed embryos. Hum Reprod. 2012;27(5):1343-50. https://doi.org/10.1093/humrep/des036 PMid:22362926

20. Kostov I, Ivanov St. Recommendation for intrapartum management of intraamniotic infections. Akusherstvo Ginekol. 2018;57(2):50-6.

21. Yunakova M, Surcheva H, Andreeva P, Veleva G, Kostov I, Shterev A. Comparison of prognostic value of markers of ovarian reserve. Akusherstvo Ginekol. 2017;56(6):3-9.

22. Yanaihara A, Ohgi S, Motomura K, Hirano A, Takanaka S, Yanaihara T. In vitro fertilization pregnancy is one of the risk factors for atonic bleeding in problem-free pregnancy. J Pregnancy Child Health. 2017;4(1):1000308. 